\title{
Ordering Cost Reduction in Inventory Model with Defective Items and Backorder Price Discount
}

\author{
Karuppuchamy Annadurai ${ }^{1}$ and Ramasamy Uthayakumar ${ }^{2}$ \\ ${ }^{1}$ Department of Mathematics, Government Arts College, Udumalpet, Tamil Nadu 642 126, India \\ ${ }^{2}$ Department of Mathematics, Gandhigram Rural University, Gandhigram, Tamil Nadu 624302, India
}

Correspondence should be addressed to Karuppuchamy Annadurai; anna.vadivu@gmail.com

Received 31 May 2014; Accepted 21 October 2014; Published 12 November 2014

Academic Editor: Eric S. Fraga

Copyright ( $) 2014$ K. Annadurai and R. Uthayakumar. This is an open access article distributed under the Creative Commons Attribution License, which permits unrestricted use, distribution, and reproduction in any medium, provided the original work is properly cited.

\begin{abstract}
In the real market, as unsatisfied demands occur, the longer the length of lead time is, the smaller the proportion of backorder would be. In order to make up for the inconvenience and even the losses of royal and patient customers, the supplier may offer a backorder price discount to secure orders during the shortage period. Also, ordering policies determined by conventional inventory models may be inappropriate for the situation in which an arrival lot contains some defective items. To compensate for the inconvenience of backordering and to secure orders, the supplier may offer a price discount on the stockout item. The purpose of this study is to explore a coordinated inventory model including defective arrivals by allowing the backorder price discount and ordering cost as decision variables. There are two inventory models proposed in this paper, one with normally distributed demand and another with distribution free demand. A computer code using the software Matlab 7.0 is developed to find the optimal solution and present numerical examples to illustrate the models. The results in the numerical examples indicate that the savings of the total cost are realized through ordering cost reduction and backorder price discount.
\end{abstract}

\section{Introduction}

In real life, the occurrence of shortage in an inventory system is phenomenon. Under the most market behaviors, we can often observe that many products of famous brands or fashionable goods such as certain brand gum shoes, hi-fi equipment, and clothes may lead to a situation in which customers may prefer to wait for backorders while shortages occur. Besides the product, the image of selling shop is one of the potential factors that will motivate the customers intention of backorders. To establish the good image and enhance customers' loyalty, the selling shop could invest in upgrading the servicing facilities, maintaining the high quality of selling products and spending money on advertisement. Other endeavors, such as mailing the greeting card and providing free gift, can also be done to establish a good relationship with their customers. We note that such type of activities is not certainly free. Naturally, an extraadded cost must be spent for these efforts. Further it is expected to have a result to reduce the shortage cost of lost-sales and the total expected annual cost. Under the situation, for a vendor, how to control an appropriate length of lead time to determine a target value of backorder rate so as to minimize the relevant inventory cost and increase the competitive edge in business is worth discussing. As a result by shortening the lead time, we can lower the safety stock, reduce the stockout loss, and improve the service level to the customers so as to increase the competitive edge in business. The issue of lead time reduction has received a lot of interest in recent years. With such characteristics, researchers have modified traditional inventory models to incorporate the implementation of lead time concepts.

Liao and Shyu [1] presented a probabilistic inventory model in which the lead time is a unique decision variable and the order quantity is predetermined. Ben-Daya and Raouf [2] extended this model by considering both lead time and order quantity as decision variables. Ouyang and $\mathrm{Wu}$ [3] assumed the lead time demand to be any cumulative distribution with known and finite first and second moments, and a procedure is developed to find the optimal lead time 
and the optimal order quantity for the inventory problem with a mixture of backorders and lost-sales. Ouyang et al. [4] presented a continuous review inventory system with partial backorders by considering both the lead time and the ordering cost as decision variables. Ouyang and Chuang [5] considered a mixed periodic review inventory model in which both the lead time and the review period are considered as decision variables. Ouyang et al. [6] formulated and solved an integrated inventory model with controllable lead time. A lot of work has been done to develop some optimization models and algorithms in various decision environments for continuous inventory problems with variable lead time, such as Yang et al. [7], Lee [8], Hoque and Goyal [9], and Annadurai and Uthayakumar [10].

As unsatisfied demands occur, practically, we can often observe that some customers may prefer their demands to be backordered, and some may refuse the backorder case. There is a potential factor that may motivate the customers' desire for backorders. The factor is an offering of a backorder price discount. In general, provided that a supplier could offer a backorder price discount on the stockout item by negotiation to secure more backorders, it may make the customers more willing to wait for the desired items. In other words, the bigger the backorder price discount, the bigger the advantage to the customers, and, hence, a larger number of backorder ratios may be the result. Pan and Hsiao [11] presented integrated inventory model with controllable lead time and backorder discount considerations. Lee et al. [12] developed a joint inventory decision model with variable lead time and ordering cost. Lin [13] analyzed the inventory model in which the lead time and ordering cost reductions are interdependent in the continuous review inventory model with backorder price discount. In the research conducted by Uthayakumar and Parvathi [14], not only lead time and setup cost, but also yield variability was assumed to be variable. Besides, the backorder rate was assumed to be controllable through the amount of expected shortage. In their models, all the capital investments were assumed to be subject to logarithmic function. In a recent paper, Annadurai and Uthayakumar [10] took the imperfect quality into account and developed a continuous review inventory model involving variable lead time and setup cost. In their paper, they discussed normal distribution model and distributionfree model. Sarkar et al. [15] derived an EOQ model for various types of time-dependent demand when delay in payment and price discount are permitted by suppliers to retailers.

In reality all manufacturing industries try to produce products with acceptable quality but in the long run it is difficult to produce perfect quality items due to various causes like machine breakdowns, labor problems, and shortages of raw materials. In the classical inventory model, it is implicitly assumed that the quality level is fixed at an optimal level; that is, all items are assumed to have perfect quantity. However, in the real production environment, it can often be observed that there are defective items being produced due to imperfect processes. The defective items must be rejected, repaired, reworked, or, if they have reached the customer, refunded.
In all cases, substantial costs are incurred. Paknejad et al. [16] presented a quality-adjusted lot-sizing model with stochastic demand and constant lead time. In their paper, the shortages are allowed and fully backordered and the defective rate in an order lot is fixed. Ouyang and $\mathrm{Wu}$ [17] considered lead time and order quantity as decision variables for the mixture of lost-sales and backorder inventory model with shortages. Wu and Ouyang [18] studied $(Q, r, L)$ inventory model with defective items. In their paper, they derived a modified mixture inventory model with backorders and lostsales, in which the order quantity, the reorder point, and the lead time are decision variables. Sana et al. [19] derived an imperfect production process in a volume flexible inventory model with reduced selling price for defective items. Sarkar et al. [20] discussed an inventory model in an imperfect production process and employed the control theory to obtain an optimal solution. Sarkar et al. [21] established an EPQ model with stochastic demand with the production of defective items. Lee et al. [22] developed a computational procedure of an inventory model with defective units where the order quantity and lead time are assumed as decision variables. In a recent paper, Skouri et al. [23] considered a single-echelon inventory installation under the classical EOQ model with backorders and studied the effects of supply quality on cost performance. In their paper they discussed an alternative setting where entire supply batches may be defective (below quality standards) and therefore rejected on arrival.

However, to the best of our knowledge, there exists no literature considering the collaborative inventory system in a supply chain with defective arrival units and backorder price discount. Therefore, the paper focuses on establishing collaborative inventory system under the above said concepts. Therefore, the proposed model further fits a more general inventory feature in many real-life situations. In this paper we develop an inventory model including defective arrivals by allowing the backorder price discount as a decision variable. It is assumed that the supplier may offer a backorder price discount to the patient customers with outstanding orders during the shortage period to secure customer orders. Furthermore, the inventory lead time can be shortened at an extra crashing cost and ordering cost can also be reduced by capital investment. We discuss two models, namely, one with normally distributed demand and the other with generally distributed demand. For each model, we develop a separate computational algorithm with the help of the software Matlab 7.0 to find the optimal ordering strategy.

The remainder of this paper is organized as follows. Section 2 describes the notations and assumptions employed throughout this paper. We formulate an integrated inventory model including defective arrival with backorder price discount and ordering cost reduction in Section 3. Here, both normal distribution model and distribution-free model are discussed. Furthermore, for each model, a separate algorithm is developed to obtain the optimal solution. Numerical examples are provided in Section 4 to illustrate the results. Finally, we draw some conclusions and give suggestions for future research in Section 5. 


\section{Notations and Assumptions}

The proposed model is developed based on the following assumptions and notations.

2.1. Notations. The notation is summarized in the following:

$A_{0}$ : original ordering cost before any investment is made,

$A$ : ordering cost per order, $0<A \leq A_{0}$,

Q: ordering quantity,

$D$ : annual demand,

$h$ : nondefective holding cost per unit per year,

$h^{\prime}$ : defective holding cost per unit per year,

$\pi$ : backorder price discount offered by the supplier per unit,

$\pi_{0}$ : marginal profit per unit,

$L$ : length of lead time,

$\nu$ : unit inspection cost,

$\beta$ : fraction of the demand during the stockout period that will be backordered $0 \leq \beta<1$,

$\beta_{0}$ : upper bound of the backorder ratio,

$p$ : defective rate in an order lot, $p \in[0,1)$, a random variable,

$g(p)$ : the probability density function of $p$,

$\theta_{0}$ : fractional annual opportunity cost of capital,

$x^{+}$: maximum value of $x$ and 0 ; that is, $x^{+}=$ $\operatorname{Max}\{x, 0\}$,

$E(\cdot)$ : mathematical expectation,

$X$ : the lead time demand which has a probability density function $f_{X}$ with finite mean $D L$ and standard deviation $\sigma \sqrt{L}$,

$\Omega$ : the class of the cumulative distribution function $f_{X}$ with finite mean $D L$ and standard deviation $\sigma \sqrt{L}$.

2.2. Assumptions. We assume the following assumptions to develop our model.

(1) Inventory is continuously reviewed. Replenishments are made whenever the inventory level (based on the number of nondefective items) falls to the reorder point $r$.

(2) An arrival may contain some defective items. We assume that the number of defective items in an arriving order of size $Q$ is a binomial random variable with parameters $Q$ and $p$, where $p(0 \leq p<1)$ represents the defective rate in an order lot. Upon arrival of an order, all the items are inspected and defective items in each lot will be returned to the vendor at the time of delivery of the next lot.
(3) The reorder point $r=$ expected demand during lead time + safety stock SS, and SS $=k \times$ (standard deviation of lead time demand); that is, $r=D L+k \sigma \sqrt{L}$, where $k$ is the safety factor.

(4) The lead time $L$ consists of $n$ mutually independent components. The $i$ th component has a minimum duration $a_{i}$, normal duration $b_{i}$, and a crashing cost per unit time $c_{i}$. Further, for our convenience, we rearrange $c_{i}$ such that $c_{1} \leq c_{2} \leq c_{3} \cdots \leq c_{n}$.

(5) The components of lead time are crashed one at a time starting with component 1 (because it has the minimum unit crashing cost), then component 2 , and so on.

(6) Let $L_{0}=\sum_{j=1}^{n} b_{j}$ and let $L_{i}$ be the length of lead time with components $1,2, \ldots, i$ crashed to their minimum duration. Then $L_{i}$ can be expressed as $L_{i}=\sum_{j=1}^{n} b_{j}-$ $\sum_{j=1}^{i}\left(b_{j}-a_{j}\right), i=1,2, \ldots, n$, and the lead time crashing cost $C(L)$ per cycle for a given $L \in\left[L_{i}, L_{i-1}\right]$ is given by $C(L)=c_{i}\left(L_{i-1}-L\right)+\sum_{j=1}^{i-1} c_{j}\left(b_{j}-a_{j}\right)$.

(7) The supplier makes decisions in order to obtain profits. Therefore, if the price discount $\pi$ is greater than the marginal profit $\pi_{0}$ then the supplier may decide against offering the price discount.

(8) During the stockout period, the backorder ratio $\beta$ is variable and is proportional to the backorder price discount $\pi$ offered by the supplier per unit. Thus, $\beta=$ $\beta_{0} \pi / \pi_{0}$, where $0 \leq \beta_{0}<1$ and $0 \leq \pi \leq \pi_{0}$ (see Pan and Hsiao [11]).

(9) Upon an arrival order lot $Q$ with a defective rate $p$, the entire items are inspected and all defective items are assumed to be discovered and removed from order quantity $Q$. Thus, the effective order quantity (i.e., the quantity of nondefective or salable items) is reduced to an amount equal to $Q(1-p)$.

(10) Inspection is nondestructive and error-free.

\section{Mathematical Formulation}

We assume that the lead time demand $X$ has the p.d.f. $f_{X}(x)$ with finite mean $D L$ and standard deviation $\sigma \sqrt{L}$. With backorder ratio $\beta$, expected number of backorders per cycle is $\beta E(X-r)^{+}$, where $E(X-r)^{+}$is the expected demand shortage at the end of cycle and the annual stockout cost is $(D / Q)\left[\pi \beta+\pi_{0}(1-\beta)\right] E(X-r)^{+}$. The expected net inventory level just before the order arrives is $\left[r-D L+(1-\beta) E(X-r)^{+}\right]$. Then, the joint total expected annual cost is composed of ordering cost, nondefective holding cost, defective holding 
cost, stockout cost, inspection cost, and lead time crashing cost and is expressed by

$$
\begin{aligned}
\operatorname{JTEAC}(Q, r, \beta, L) & \\
= & \frac{D}{Q[1-E(p)]} \\
& \times\left[A+C(L)+\left[\pi \beta+\pi_{0}(1-\beta)\right] E(X-r)^{+}+\nu Q\right] \\
+ & \frac{h}{2}\left[Q[1-E(p)]+\frac{Q\left(E\left(p^{2}\right)-E^{2}(p)\right)}{1-E(p)}\right. \\
& \left.\quad+\frac{E[p(1-p)]}{1-E(p)}\right] \\
+ & h\left[r-D L+(1-\beta) E(X-r)^{+}\right] \\
+ & h^{\prime}(Q-1) \frac{E[p(1-p)]}{1-E(p)},
\end{aligned}
$$

where $D / Q(1-E(p))$ is the expected order number per year (see, e.g., Schwaller [24]), $\int_{0}^{1} p g(p) d p$ is the mean of random variable $p$, and $E(X-r)^{+}$is the expected demand shortage at the end of cycle.

In this model, we consider the ordering cost $A$ as a decision variable and seek to minimize the sum of the capital investment cost of reducing order cost and the inventory related costs by optimizing over $Q, A, r, \beta$, and $L$ constrained $0<A \leq A_{0}$, where $A_{0}$ is the original ordering cost. Now, the supplier's capital investment is $\theta_{0} I(A)$ where $\theta_{0}$ is the fractional opportunity cost of capital per year and follows a logarithmic investment function given by $I(A)=$ $b \ln \left(A_{0} / A\right)$ for $0<A \leq A_{0}$, where $1 / b$ is the fraction of the reduction in $A$ per dollar increase in investment. This logarithmic investment function is consistent with the Japanese experience as reported in Hall [25] and has been used by Nasri et al. [26] and others. Thus, (1) becomes

$$
\begin{aligned}
\text { JTEAC } & (Q, A, r, \beta, L) \\
= & \theta_{0} b \ln \left(\frac{A_{0}}{A}\right) \\
& +\frac{D}{Q[1-E(p)]} \\
& \times\left[A+C(L)+\left[\pi \beta+\pi_{0}(1-\beta)\right] E(X-r)^{+}+\nu Q\right] \\
+ & \frac{h}{2}\left[Q[1-E(p)]+\frac{Q\left(E\left(p^{2}\right)-E^{2}(p)\right)}{1-E(p)}\right. \\
& \left.\quad+\frac{E[p(1-p)]}{1-E(p)}\right] \\
+ & h\left[r-D L+(1-\beta) E(X-r)^{+}\right] \\
+ & h^{\prime}(Q-1) \frac{E[p(1-p)]}{1-E(p)} .
\end{aligned}
$$

Moreover, during the stockout period, the backorder ratio $\beta$ is variable and is proportional to the backorder price discount $\pi$ offered by the supplier per unit. For example, $\beta=\beta_{0} \pi / \pi_{0}$, where $0 \leq \beta_{0}<1$ and $0 \leq \pi \leq \pi_{0}$. Thus the backorder price discount offered by the supplier per unit $\pi$ can be treated as a decision variable instead of the backorder ratio $\beta$. Hence (2) can be transformed into

$$
\begin{aligned}
\operatorname{JTEAC} & (Q, A, r, \pi, L) \\
= & \theta_{0} b \ln \left(\frac{A_{0}}{A}\right) \\
+ & \frac{D}{Q(1-E(p))} \\
& \times\left[A+C(L)+\left(\frac{\beta_{0} \pi^{2}}{\pi_{0}}+\pi_{0}-\beta_{0} \pi\right) E(X-r)^{+}+\nu Q\right] \\
+ & \frac{h}{2}\left\{Q(1-E(p))+\frac{\left.Q\left(p^{2}\right)-E^{2}(p)\right)}{1-E(p)}\right. \\
+ & \left.+\frac{E(p(1-p))}{1-E(p)}\right\} \\
+ & h^{\prime}(Q-1) \frac{E(p(1-p))}{1-E(p)} .
\end{aligned}
$$

3.1. Normal Distribution Model. We assume that the lead time demand $X$ follows normal distribution which has a probability density function $f_{X}(x)$ with finite mean $D L$ and standard deviation $\sigma \sqrt{L}$. We may recall that $r=D L+$ $k \sigma \sqrt{L}$, where $k$ is the safety factor and the expected shortage quantity $E(X-r)^{+}$at the end of the cycle can be expressed as $E(X-r)^{+}=\int_{r}^{\infty}(x-r)^{+} f_{X}(x) d x=\sigma \sqrt{L} \psi(k)>0$, where $\psi(k)=\varphi(k)-k[1-\Phi(k)]$ and $\varphi(k)$ and $\Phi(k)$ denote the standard normal probability density function and cumulative distribution function, respectively. Hence (3) can be transformed to

$$
\begin{aligned}
& \operatorname{JTEAC}^{N}(Q, A, k, \pi, L) \\
& =\theta_{0} b \ln \left(\frac{A_{0}}{A}\right) \\
& +\frac{D}{Q[1-E(p)]} \\
& \times\left[A+C(L)+\left(\frac{\beta_{0} \pi^{2}}{\pi_{0}}+\pi_{0}-\beta_{0} \pi\right) \sigma \sqrt{L} \psi(k)+\nu Q\right] \\
& +\frac{h}{2}\left[Q[1-E(p)]+\frac{Q\left(E\left(p^{2}\right)-E^{2}(p)\right)}{1-E(p)}\right. \\
& \left.\quad+\frac{E[p(1-p)]}{1-E(p)}\right]
\end{aligned}
$$




$$
\begin{aligned}
& +h \sigma \sqrt{L}\left[k+\left(1-\frac{\beta_{0} \pi}{\pi_{0}}\right) \psi(k)\right] \\
& +h^{\prime}(Q-1) \frac{E[p(1-p)]}{1-E(p)},
\end{aligned}
$$

over $A \in\left[0, A_{0}\right)$ where $1 \leq \beta_{0}<1$ and $0 \leq \pi \leq \pi_{0}$.

To solve this problem, taking the first order partial derivatives of $\operatorname{EAC}^{N}(Q, A, k, \pi, L)$ with respect to $Q, A, k, \pi$, and $L \in\left[L_{i}, L_{i-1}\right]$, respectively, we obtain

$$
\begin{aligned}
& \frac{\partial \operatorname{JTEAC}^{N}(Q, A, k, \pi, L)}{\partial Q} \\
& =-\frac{D\left[A+C(L)+\left(\beta_{0} \pi^{2} / \pi_{0}+\pi_{0}-\beta_{0} \pi\right) \sigma \sqrt{L} \psi(k)\right]}{Q^{2}(1-E(P))},
\end{aligned}
$$

$$
\begin{aligned}
& \frac{\operatorname{JTEAC}^{N}(Q, A, k, \pi, L)}{\partial A}=-\frac{\theta_{0} b}{A}+\frac{D}{Q(1-E(p))}, \\
& \frac{\partial \operatorname{JTEAC}^{N}(Q, A, k, \pi, L)}{\partial k} \\
& =h \sigma \sqrt{L} \\
& \quad+\left[h\left(1-\frac{\beta_{0} \pi}{\pi_{0}}\right)+\frac{D}{Q(1-E(p))}\left(\frac{\beta_{0} \pi^{2}}{\pi_{0}}+\pi_{0}-\beta_{0} \pi\right)\right] \\
& \quad \times \sigma \sqrt{L} P_{z}(k),
\end{aligned}
$$

where $P_{z}(k)=\operatorname{Pr}(z \geq k)$ and $z$ is the standard normal variable. Consider

$$
\begin{aligned}
& \frac{\partial_{\operatorname{TEAC}^{N}(Q, A, k, \pi, L)}}{\partial \pi} \\
& =\left[\frac{D}{Q(1-E(p))}\left(\frac{2 \beta_{0} \pi}{\pi_{0}}-\beta_{0}\right)-\frac{h \beta_{0}}{\pi_{0}}\right] \sigma \sqrt{L} \psi(k), \\
& \frac{\partial \operatorname{JTEAC}^{N}(Q, A, k, \pi, L)}{\partial L} \\
& =\frac{D\left(\beta_{0} \pi^{2} / \pi_{0}+\pi_{0}-\beta_{0} \pi\right) \sigma L^{-1 / 2} \psi(k)}{2 Q(1-E(P))} \\
& \quad+\frac{h \sigma L^{-1 / 2}}{2}\left[k+\left(1-\frac{\beta_{0} \pi}{\pi_{0}}\right) \psi(k)\right] \\
& \quad-\frac{D C_{i}}{Q(1-E(p))} .
\end{aligned}
$$

By examining the second order sufficient conditions, for fixed $(Q, A, k, \pi)$, $\operatorname{JTEAC}^{N}(Q, A, k, \pi, L)$ is concave in $L \in$ $\left[L_{i}, L_{i-1}\right]$ because

$$
\begin{aligned}
\frac{\partial^{2} \operatorname{JTEAC}^{N}(Q, A, k, \pi, L)}{\partial L^{2}} & \\
= & -\frac{D\left(\beta_{0} \pi^{2} / \pi_{0}+\pi_{0}-\beta_{0} \pi\right) \sigma L^{-3 / 2} \psi(k)}{4 Q(1-E(p))} \\
& -\frac{h \sigma L^{-3 / 2}}{4}\left[k+\left(1-\frac{\beta_{0} \pi}{\pi_{0}}\right) \psi(k)\right]<0 .
\end{aligned}
$$

Therefore, for fixed $(Q, A, k, \pi)$, the minimum joint total expected annual cost will occur at the end points of the interval $\left[L_{i}, L_{i-1}\right]$. On the other hand, by setting (6) equal to zero and solving for $A$, we obtain

$$
A=\frac{\theta_{0} b Q(1-E(p))}{D} .
$$

Similarly by setting (8) to zero and solving for $\pi$, we get

$$
\pi=\frac{h Q(1-E(p))}{2 D}+\frac{\pi_{0}}{2} .
$$

Substituting (12) into (5) and setting it to zero, we obtain

$$
Q=\sqrt{\frac{2 D\left[A+C(L)+\left(\pi_{0}\left(4-\beta_{0}\right) / 4\right) \sigma \sqrt{L} \psi(k)\right]}{h G\left(E_{p}\right)\left[1-\left(h \beta_{0} / 2 D \pi_{0}\right) \sigma \sqrt{L} \psi(k)\right]}},
$$

where $G\left(E_{p}\right)=1-2 E(p)+E\left(p^{2}\right)+\left(2 h^{\prime} / h\right) E(p(1-p))$. Again, substituting (12) into (7) and setting it to zero, we get

$$
\begin{aligned}
& P_{z}(k) \\
& =4 h \pi_{0} D Q(1-E(p)) \\
& \times\left(\left(4-\beta_{0}\right) \pi_{0}^{2} D^{2}+\left(4-2 \beta_{0}\right) h \pi_{0} D Q(1-E(p))\right. \\
& \left.-\beta_{0} h^{2} Q^{2}(1-E(p))\right)^{-1} \text {. }
\end{aligned}
$$

For fixed $\left[L_{i}, L_{i-1}\right]$, by solving (11)-(14), we can obtain the values of $(Q, A, k, \pi)$ (denote these values by $\left(Q^{*}, A^{*}, k^{*}, \pi^{*}\right)$, resp.). The following proposition asserts that, for fixed $\left[L_{i}, L_{i-1}\right]$, the point $\left(Q^{*}, A^{*}, k^{*}, \pi^{*}\right)$ is the optimal solution such that the joint total expected annual cost has a minimum value.

Proposition 1. For $\left[L_{i}, L_{i-1}\right]$, the Hessian matrix for $\operatorname{JTEAC}^{N}(Q, A, k, \pi, L)$ is positive definite at a point $\left(Q^{*}, A^{*}, k^{*}, \pi^{*}\right)$.

Proof. Refer to Appendix A.

In order to examine the effects of $A$ on the joint total expected annual cost, we take the second order partial derivative of $\operatorname{JTEAC}^{N}(Q, A, k, \pi, L)$ with respect to $A$ and obtain 
$\partial \operatorname{JTEAC}^{N}(Q, A, k, \pi, L) / \partial A^{2}=\theta_{0} b / A^{2}>0$. Therefore, $\operatorname{JTEAC}^{N}(Q, A, k, \pi, L)$ is convex in $A$, for fixed $(Q, k, \pi)$ and $\left[L_{i}, L_{i-1}\right]$. As a result, the search for the optimal ordering cost $A^{*}$ is reduced to find a local minimum. Since it is difficult to find an explicit general solution for $(Q, A, k, \pi)$, we establish the following computational algorithm to find the optimal solution of $(Q, A, k, \pi, L)$ denoted by $\left(Q^{*}, A^{*}, k^{*}, \pi^{*}, L^{*}\right)$.

Computational Algorithm 1. One has the following.

Step 1. For each $L_{i}, i=0,1,2, \ldots, n$, perform Step 1.1 to Step 1.5 .

Step 1.1. Start with $k_{i 1}=0$ and $A_{i 1}=A_{0}$.

Step 1.2. Substituting $\psi\left(k_{i 1}\right)$ and $A_{i 1}$ into (13) evaluates $Q_{i}$.

Step 1.3. With the help of $Q_{i}$ determine $A_{i 2}$ from (11), $\pi_{i}$ from (12), and $P_{z}\left(k_{i 2}\right)$ from (14).

Step 1.4. Checking $P_{z}\left(k_{i 2}\right)$ from normal table, find $k_{i 2}$ and hence $\psi\left(k_{i 2}\right)$.

Step 1.5. Repeat Steps 1.2 to 1.4 until no change occurs in the values of $Q_{i}, A_{i}, \pi_{i}$, and $k_{i}$.

Step 2. Compare $A_{i}$ with $A_{0}$ and $\pi_{i}$ with $\pi_{0}$.

Step 2.1. If $A_{i} \leq A_{0}$ and $\pi_{i} \leq \pi_{0}$, then $A_{i}$ and $\pi_{i}$ are feasible. Go to Step 3.

Step 2.2. If $A_{i}>A_{0}$ or $\pi_{i}>\pi_{0}$, then $A_{i}$ and $\pi_{i}$ are not feasible. For given $L_{i}$, take $A_{i}=A_{0}$ and $\pi_{i}=\pi_{0}$ and solve the corresponding values of $\left(Q_{i}, k_{i}, \pi_{i}\right)$ from (13), (14), and (12) iteratively until convergence, and then go to Step 3.

Step 3. For each $\left(Q_{i}, A_{i}, k_{i}, \pi_{i}, L_{i}\right), i=0,1,2, \ldots, n$, compute the corresponding joint total expected annual cost $\operatorname{JTEAC}^{N}\left(Q_{i}, A_{i}, k_{i}, \pi_{i}, L_{i}\right)$ by utilizing (4).

Step 4. Find the value of $\operatorname{Min}_{i=0,1,2, \ldots, n} \mathrm{JTEAC}^{N}$ $\left(Q_{i}, A_{i}, k_{i}, \pi_{i}, L_{i}\right)$ and set $\operatorname{JTEAC}^{N}\left(Q^{*}, A^{*}, k^{*}, \pi^{*}, L^{*}\right)=$ $\left.\operatorname{Min}_{i=0,1,2, \ldots, n}\right) \operatorname{TEAC}^{N}\left(Q_{i}, A_{i}, k_{i}, \pi_{i}, L_{i}\right)$ and then $\left(Q^{*}, A^{*}, k^{*}\right.$, $\left.\pi^{*}, L^{*}\right)$ is the optimal solution.

Once we have optimal solution $\left(Q^{*}, A^{*}, k^{*}, \pi^{*}, L^{*}\right)$, then the optimal reorder point $r^{*}=D L^{*}+k^{*} \sigma \sqrt{L^{*}}$ is obtained.

3.2. Distribution-Free Model. In practical problems, the probability distribution of the lead time demand information is often quite limited. A decision maker can identify the mean value and variance of the lead time demand. But the exact probability distribution may be unknown. Due to insufficient information, the expected shortage $E(X-r)^{+}$value is unknown and, hence, the optimal value of $(Q, A, k, \pi, L)$ cannot be found. To overcome this problem, the assumption about the normal distribution of the lead time demand is relaxed and we only assume that the lead time demand $X$ has been given with finite first two moments. For example, The p.d.f. $f_{X}$ of $X$ belongs to the class $\Omega$ of p.d.f.s with finite mean $D L$ and standard deviation $\sigma \sqrt{L}$. Hence, we use the minimax distribution-free procedure to solve this problem. The minimax distribution-free approach for this problem is to find the most favorable p.d.f. $f_{X}$ in $\Omega$ for each $(Q, A, k, \pi, L)$ and then minimize the joint total expected annual cost over $(\mathrm{Q}, A, k, \pi, L)$. For example, our problem is to solve

$$
\underset{(Q, A, k, \pi, L)}{\operatorname{Min}} \operatorname{Max}_{f_{X} \in \Omega} \operatorname{JTEAC}(Q, A, k, \pi, L) .
$$

For this purpose, we need the following proposition which was asserted by Gallego and Moon [27].

Proposition 2. For any $f_{X} \in \Omega$,

$$
E(X-r)^{+} \leq \frac{1}{2}\left\{\sqrt{\sigma^{2} L+(r-D L)^{2}}-(r-D L)\right\} .
$$

Moreover, the upper bound (16) is tight.

Substituting $r=D L+k \sigma \sqrt{L}$, we have

$$
E(X-r)^{+} \leq \frac{1}{2} \sigma \sqrt{L}\left(\sqrt{1+k^{2}}-k\right),
$$

and, for any probability distribution of the lead time demand $X$, the above inequality (17) always holds. Then using the inequality (17) and (3) and considering the safety factor $k$ as a decision variable instead of $r$, the cost function can be expressed to minimize

$$
\begin{aligned}
& \operatorname{JTEAC}^{U}(Q, A, k, \pi, L) \\
& \begin{array}{l}
\theta_{0} b \ln \left(\frac{A_{0}}{A}\right)+\frac{D}{Q[1-E(p)]}[A+C(L)+\nu Q] \\
+\frac{h}{2}\left\{2 k \sigma \sqrt{L}+Q[1-E(p)]+\frac{Q\left(E\left(p^{2}\right)-E^{2}(p)\right)}{1-E(p)}\right. \\
\left.\quad+\frac{E[p(1-p)]}{1-E(p)}\right\} \\
+\frac{1}{2}\left\{\frac{D}{Q[1-E(p)]}\left(\frac{\beta_{0} \pi^{2}}{\pi_{0}}+\pi_{0}-\beta_{0} \pi\right)+h\left(1-\frac{\beta_{0} \pi}{\pi_{0}}\right)\right\} \\
\times \sigma \sqrt{L}\left(\sqrt{1+k^{2}}-k\right),
\end{array}
\end{aligned}
$$

over $A \in\left[0, A_{0}\right)$ where $1 \leq \beta_{0}<1$ and $0 \leq \pi \leq \pi_{0}$ and $\operatorname{JTEAC}^{U}(Q, A, k, \pi, L)$ is the total expected annual cost for the distribution-free case and is the least upper bound of $(Q, A, k, \pi, L)$. Take the first order partial derivatives of 
$\operatorname{JTEAC}^{U}(Q, A, k, \pi, L)$ with respect to $Q, A, k, \pi$, and $L \in$ $\left[L_{i}, L_{i-1}\right]$, respectively; we obtain

$$
\begin{gathered}
\frac{\partial \operatorname{JTEAC}^{U}(Q, A, k, \pi, L)}{\partial Q} \\
=-\left(D \left[A+C(L)+\frac{1}{2}\left(\frac{\beta_{0} \pi^{2}}{\pi_{0}}+\pi_{0}-\beta_{0} \pi\right)\right.\right. \\
\left.\times \sigma \sqrt{L}\left(\sqrt{1+k^{2}}-k\right)\right] \\
\left.\times\left(Q^{2}(1-E(P))\right)^{-1}\right) \\
+\frac{h}{2}\left\{(1-E(p))+\frac{\left(E\left(p^{2}\right)-E^{2}(p)\right)}{1-E(p)}\right\} \\
+h^{\prime} \frac{E(p(1-p))}{1-E(p)}, \\
\frac{\partial \mathrm{JTEAC}^{U}(Q, A, k, \pi, L)}{\partial A}=-\frac{\theta_{0} b}{A}+\frac{D}{Q(1-E(p))}, \\
\frac{\partial \mathrm{JTEAC}^{U}(Q, A, k, \pi, L)}{\partial k} \\
\times \sigma \sqrt{L}\left(1-\frac{k}{\sqrt{1+k^{2}}}\right), \\
h \sigma \sqrt{L}-\frac{1}{2}\left[h\left(1-\frac{\beta_{0}}{\pi_{0}} \pi\right)\right. \\
\left.\left.\frac{D(1-E(p))}{\pi_{0}} \pi^{2}+\pi_{0}-\beta_{0} \pi\right)\right]
\end{gathered}
$$$$
\frac{\partial \operatorname{JTEAC}^{U}(Q, A, k, \pi, L)}{\partial \pi}
$$$$
=\left[\frac{D}{Q(1-E(p))}\left(\frac{2 \beta_{0} \pi}{\pi_{0}}-\beta_{0}\right)-\frac{h \beta_{0}}{\pi_{0}}\right]
$$$$
\times \sigma \sqrt{L}\left(\sqrt{1+k^{2}}-k\right),
$$

$$
\begin{aligned}
& \frac{\partial \operatorname{JTEAC}^{U}(Q, A, k, \pi, L)}{\partial L} \\
& =\frac{1}{4}\left[h\left(1-\frac{\beta_{0}}{\pi_{0}} \pi\right)+\frac{D}{Q(1-E(p))}\left(\frac{\beta_{0}}{\pi_{0}} \pi^{2}+\pi_{0}-\beta_{0} \pi\right)\right] \\
& \quad \times \sigma L^{-1 / 2}\left(\sqrt{1+k^{2}}-k\right)+\frac{1}{2} h k \sigma L^{-1 / 2}-\frac{D C_{i}}{Q(1-E(p))} .
\end{aligned}
$$

By examining the second order sufficient conditions, for fixed $(Q, A, k, \pi), \operatorname{JTEAC}^{N}(Q, A, k, \pi, L)$ is concave in $L \in\left[L_{i}, L_{i-1}\right]$ because

$$
\begin{aligned}
& \frac{\partial \operatorname{JTEAC}^{U}(Q, A, k, \pi, L)}{\partial L^{2}} \\
& =-\frac{1}{8}\left[h\left(1-\frac{\beta_{0}}{\pi_{0}} \pi\right)+\frac{D}{Q(1-E(p))}\left(\frac{\beta_{0}}{\pi_{0}} \pi^{2}+\pi_{0}-\beta_{0} \pi\right)\right] \\
& \quad \times \sigma L^{-3 / 2}\left(\sqrt{1+k^{2}}-k\right)-\frac{1}{4} h k \sigma L^{-3 / 2}<0 .
\end{aligned}
$$

Therefore, as in the normal distribution case, here also, for fixed $(Q, A, k, \pi)$, the minimum joint total expected annual cost will occur at the end points of the interval $\left[L_{i}, L_{i-1}\right]$. On the other hand, by setting (20) equal to zero and solving for $A$, we obtain

$$
A=\frac{\theta_{0} b Q(1-E(p))}{D} .
$$

Similarly by setting (22) to zero and solving for $\pi$, we get

$$
\pi=\frac{h Q(1-E(p))}{2 D}+\frac{\pi_{0}}{2} .
$$

Again, substituting (26) into (19) and setting it to zero, we get Q

$$
=\sqrt{\frac{2 D\left[A+C(L)+\left(\pi_{0}\left(4-\beta_{0}\right) / 8\right) \sigma \sqrt{L}\left(\sqrt{1+k^{2}}-k\right)\right]}{h G\left(E_{p}\right)\left[1-\left(h \beta_{0} / 4 D \pi_{0}\right) \sigma \sqrt{L}\left(\sqrt{1+k^{2}}-k\right)\right]}},
$$

where $G\left(E_{p}\right)=1-2 E(p)+E\left(p^{2}\right)+\left(2 h^{\prime} / h\right) E(p(1-p))$.

Substituting (26) into (21) and setting it to zero, we get

$$
\begin{aligned}
1- & \frac{k}{\sqrt{1+k^{2}}} \\
= & 8 h \pi_{0} D Q(1-E(p)) \\
& \times\left(\left(4-\beta_{0}\right) \pi_{0}^{2} D^{2}+\left(4-2 \beta_{0}\right) h \pi_{0} D Q(1-E(p))\right. \\
& \left.\quad-\beta_{0} h^{2} Q^{2}(1-E(p))\right)^{-1} .
\end{aligned}
$$

For fixed $\left[L_{i}, L_{i-1}\right]$, by solving (25)-(28), we can obtain the values of $(Q, A, k, \pi)$ (denote these values by $\left(Q_{*}, A_{*}, k_{*}, \pi_{*}\right)$, resp.). The following proposition asserts that, for fixed $\left[L_{i}, L_{i-1}\right]$, the point $\left(Q_{*}, A_{*}, k_{*}, \pi_{*}\right)$ is the optimal solution such that the joint total expected annual cost has a minimum value.

Proposition 3. For $\left[L_{i}, L_{i-1}\right]$, the Hessian matrix for $\operatorname{JTEAC}^{U}(Q, A, k, \pi, L)$ is positive definite at a point $\left(Q_{*}, A_{*}, k_{*}, \pi_{*}\right)$.

Proof. Refer to Appendix B. 
In order to examine the effects of $A$ on the joint total expected annual cost, we take the second order partial derivative of $\operatorname{JTEAC}^{U}(Q, A, k, \pi, L)$ with respect to $A$ and obtain $\partial \operatorname{JTEAC}^{U}(Q, A, k, \pi, L) / \partial A^{2}=\theta_{0} b / A^{2}>0$. Therefore, $\operatorname{JTEAC}^{U}(Q, A, k, \pi, L)$ is convex in $A$, for fixed $(Q, k, \pi)$ and $\left[L_{i}, L_{i-1}\right]$. As a result, the search for the optimal ordering cost $A_{*}$ is reduced to find a local minimum. Since it is difficult to find an explicit general solution for $(Q, A, k, \pi)$, we establish the following computational algorithm to find the optimal solution of $(Q, A, k, \pi, L)$ denoted by $\left(Q_{*}, A_{*}, k_{*}, \pi_{*}, L_{*}\right)$.

Computational Algorithm 2. One has the following.

Step 1. For each $L_{i}, i=0,1,2, \ldots, n$, perform Step 1.1 to Step 1.4 .

Step 1.1. Start with $k_{i 1}=0$ and $A_{i 1}=A_{0}$.

Step 1.2. Substituting $A_{i 1}$ into (27) evaluates $Q_{i 1}$.

Step 1.3. With the help of $Q_{i 1}$ determine $A_{i 2}$ from (25), $\pi_{i}$ from (26), and $k_{i 2}$ from (28).

Step 1.4. Repeat Steps 1.2 to 1.3 until no change occurs in the values of $Q_{i}, A_{i}, \pi_{i}$, and $k_{i}$.

Step 2. Compare $A_{i}$ with $A_{0}$ and $\pi_{i}$ with $\pi_{0}$.

Step 2.1. If $A_{i} \leq A_{0}$ and $\pi_{i} \leq \pi_{0}$, then $A_{i}$ and $\pi_{i}$ are feasible. Go to Step 3.

Step 2.2. If $A_{i}>A_{0}$ or $\pi_{i}>\pi_{0}$, then $A_{i}$ and $\pi_{i}$ are not feasible. For given $L_{i}$, take $A_{i}=A_{0}$ and $\pi_{i}=\pi_{0}$ and solve the corresponding values of $\left(Q_{i}, k_{i}, \pi_{i}\right)$ from (27), (28), and (26) iteratively until convergence, and then go to Step 3.

Step 3. For each $\left(Q_{i}, A_{i}, k_{i}, \pi_{i}, L_{i}\right), i=0,1,2, \ldots, n$, compute the corresponding joint total expected annual cost $\operatorname{JTEAC}^{U}\left(Q_{i}, A_{i}, k_{i}, \pi_{i}, L_{i}\right)$ by utilizing (18).

Step 4. Find the value of $\operatorname{Min}_{i=0,1,2, \ldots, n} \operatorname{JTEAC}^{U}\left(Q_{i}, A_{i}, k_{i}, \pi_{i}\right.$, $\left.L_{i}\right)$ and set $\operatorname{JTEAC}^{N}\left(Q_{*}, A_{*}, k_{*}, \pi_{*}, L_{*}\right)=\operatorname{Min}_{i=0,1,2, \ldots, n}$ $\operatorname{JTEAC}^{U}\left(Q_{i}, A_{i}, k_{i}, \pi_{i}, L_{i}\right)$; then $\left(Q_{*}, A_{*}, k_{*}, \pi_{*}, L_{*}\right)$ is the optimal solution.

Once we have the optimal solution $\left(Q_{*}, A_{*}, k_{*}, \pi_{*}\right)$, then the optimal reorder point $r_{*}=D L_{*}+k_{*} \sigma \sqrt{L_{*}}$ is obtained.

\section{Numerical Examples}

In order to illustrate the proposed solution procedure and the effects of ordering cost reduction by investment as well as lost-sales rate reduction through backorder price discount, let us consider an inventory item with the same data as in Pan and Hsiao [11].

$D=600$ units per year, $A_{0}=200 \$$ per order, $h=20 \$$ per unit per year, $h^{\prime}=12 \$$ per unit per year, $\pi_{0}=150 \$$ per unit lost, and $\sigma=7$ units per week, where 1 year $=52$ weeks and $v=1.6 \$$ per unit. For ordering cost reduction, we take $\theta_{0}=0.1$ and $b=5800$. The lead time has three components
TABLE 1: Lead time data.

\begin{tabular}{lccc}
\hline $\begin{array}{l}\text { Lead time } \\
\text { component }\end{array}$ & $\begin{array}{c}\text { Normal } \\
\text { duration } \\
b_{i} \text { (days) }\end{array}$ & $\begin{array}{c}\text { Minimum } \\
\text { duration } \\
a_{i} \text { (days) }\end{array}$ & $\begin{array}{c}\text { Unit crashing } \\
\text { cost } \\
c_{i} \text { (\$/day) }\end{array}$ \\
\hline 1 & 20 & 6 & 0.4 \\
2 & 20 & 6 & 1.2 \\
3 & 16 & 9 & 5.0 \\
\hline
\end{tabular}

with data shown in Table 1 . Besides, the defective rate $p$ in an order lot has a beta distribution with parameters $s=1$ and $t=4$; for example, the p.d.f. of $p$ is

$$
g(p)= \begin{cases}4(1-p)^{3}, & 0<p<1 \\ 0, & \text { otherwise }\end{cases}
$$

Hence, the mean of $p$ is $E(p)=s /(s+t)=0.2$ and $E\left(p^{2}\right)=$ $s(s+1) /(s+t)(s+t+1)=0.0667$ and the variance is equal to $E\left(p^{2}\right)-E^{2}(p)=0.02667$.

Example 1. Suppose that the lead time demand follows a normal distribution. Applying the proposed computational algorithm 1 yields the results shown in Table 2 for $\beta_{0}=$ $0.2,0.4,0.6,0.8$. Further, a summary of the optimal solutions is tabulated in Table 3 and to see the effects of ordering cost reduction as well as backorder price discount, we list the results of model with fixed ordering cost and without backorder price discount in the same table. From Table 3, comparing our new model with that of fixed ordering cost and without backorder price discount case, we observe the savings, which range from $18.48 \%$ to $20.01 \%$.

Example 2. The data is the same as in Example 1, except that the probability distribution of the lead time demand is unknown. Applying computational Algorithm 2, we obtain the results shown in Table 4 and the summarized optimal values are tabulated in Table 5. Here also for comparison, the optimal results of the no-investment policy (without backorder price discount) are listed in the same table. The results of Table 5 show that, for the worst distribution of the lead time demand, it is advisable to invest in ordering cost reduction and allow backorder price discount to secure orders during the shortage period. From Table 5, comparing our new model with that of no-investment case, we observe that $15.84 \%$ to $18.45 \%$ of savings can be achieved due to ordering cost reduction as well as backorder price discount.

From the above examples, it is noted that the savings of joint total expected annual cost are realized through ordering cost reduction and backorder price discount. It is also seen that when the upper bound of the backorder ratio $\beta_{0}$ increases, joint total expected annual cost decreases.

Furthermore, we examine the performance of distribution-free approach against the normal distribution. If we utilize the solution $\left(Q_{*}, A_{*}, k_{*}, \pi_{*}, L_{*}\right)$ obtained by the distribution-free case instead of utilizing $\left(Q^{*}, A^{*}, k^{*}, \pi^{*}, L^{*}\right)$ for the normal distribution model, then the added cost will be $\operatorname{JTEAC}^{N}\left(Q_{*}, A_{*}, k_{*}, \pi_{*}, L_{*}\right)-\operatorname{JTEAC}^{N}\left(Q^{*}, A^{*}, k^{*}, \pi^{*}, L^{*}\right)$. 
TABLE 2: Solution procedure of Example 1 ( $L_{i}$ in weeks).

\begin{tabular}{|c|c|c|c|c|c|c|c|}
\hline$\beta_{0}$ & $L_{i}$ & $C\left(L_{i}\right)$ & $Q_{i}$ & $A_{i}$ & $r_{i}$ & $\pi_{i}$ & $\operatorname{JTEAC}^{N}\left(Q^{*}, A^{*}, k^{*}, \pi^{*}, L^{*}\right)$ \\
\hline \multirow{4}{*}{0.2} & 8 & 0 & 83 & 68 & 164 & 75.74 & 3981.45 \\
\hline & 6 & 5.6 & 97 & 72 & 133 & 75.67 & 3792.34 \\
\hline & 4 & 22.4 & 112 & 80 & 114 & 75.40 & 3684.56 \\
\hline & 3 & 57.4 & 121 & 92 & 98 & 75.31 & 3741.71 \\
\hline \multirow{4}{*}{0.4} & 8 & 0 & 85 & 69 & 160 & 75.81 & 3842.64 \\
\hline & 6 & 5.6 & 97 & 72 & 129 & 75.41 & 3780.53 \\
\hline & 4 & 22.4 & 115 & 80 & 108 & 75.36 & 3622.36 \\
\hline & 3 & 57.4 & 121 & 92 & 91 & 75.12 & 3791.89 \\
\hline \multirow{4}{*}{0.6} & 8 & 0 & 85 & 69 & 157 & 75.84 & 3763.51 \\
\hline & 6 & 5.6 & 96 & 72 & 123 & 75.38 & 3692.46 \\
\hline & 4 & 22.4 & 116 & 80 & 106 & 75.18 & 3543.28 \\
\hline & 3 & 57.4 & 121 & 93 & 88 & 75.09 & 3699.63 \\
\hline \multirow{4}{*}{0.8} & 8 & 0 & 88 & 70 & 140 & 75.92 & 3701.46 \\
\hline & 6 & 5.6 & 96 & 73 & 118 & 75.21 & 3600.24 \\
\hline & 4 & 22.4 & 116 & 81 & 103 & 75.11 & 3490.32 \\
\hline & 3 & 57.4 & 122 & 93 & 84 & 75.02 & 3578.41 \\
\hline
\end{tabular}

TABLE 3: Summary of the optimal solutions of Example 1 ( $L_{i}$ in weeks).

\begin{tabular}{lccccccccccc}
\hline$\beta_{0}$ & \multicolumn{4}{c}{ The proposed model } & \multicolumn{4}{c}{ Model with fixed $A$ and without $\pi$} \\
& $L^{*}$ & $Q^{*}$ & $A^{*}$ & $r^{*}$ & $\pi^{*}$ & JTEAC $(\cdot)$ & $L^{*}$ & $r^{*}$ & $Q^{*}$ & EAC $(\cdot)$ & Saving $(\%)$ \\
\hline 0.2 & 4 & 112 & 80 & 114 & 75.40 & 3684.56 & 4 & 132 & 76 & 4519.96 & 18.48 \\
0.4 & 4 & 115 & 80 & 108 & 75.36 & 3622.36 & 4 & 132 & 73 & 4470.70 & 18.97 \\
0.6 & 4 & 116 & 80 & 106 & 75.18 & 3543.28 & 4 & 133 & 70 & 4420.67 & 19.85 \\
0.8 & 4 & 116 & 81 & 103 & 75.11 & 3490.32 & 4 & 133 & 67 & 4363.56 & 20.01 \\
\hline
\end{tabular}

TABLE 4: Solution procedure of Example 2 ( $L_{i}$ in weeks).

\begin{tabular}{|c|c|c|c|c|c|c|c|}
\hline$\beta_{0}$ & $L_{i}$ & $C\left(L_{i}\right)$ & $Q_{i}$ & $A_{i}$ & $r_{i}$ & $\pi_{i}$ & $\operatorname{JTEAC}^{U}\left(Q_{*}, A_{*}, k_{*}, \pi_{*}, L_{*}\right)$ \\
\hline \multirow{4}{*}{0.2} & 8 & 0 & 154 & 135 & 160 & 81.72 & 5151.23 \\
\hline & 6 & 5.6 & 140 & 124 & 138 & 81.68 & 5042.41 \\
\hline & 4 & 22.4 & 121 & 120 & 107 & 81.41 & 4832.53 \\
\hline & 3 & 57.4 & 123 & 122 & 94 & 81.32 & 4795.67 \\
\hline \multirow{4}{*}{0.4} & 8 & 0 & 149 & 121 & 151 & 81.75 & 4773.43 \\
\hline & 6 & 5.6 & 136 & 114 & 130 & 81.71 & 4616.13 \\
\hline & 4 & 22.4 & 116 & 112 & 96 & 81.46 & 4501.39 \\
\hline & 3 & 57.4 & 118 & 116 & 82 & 81.38 & 4467.81 \\
\hline \multirow{4}{*}{0.6} & 8 & 0 & 138 & 110 & 143 & 81.86 & 4450.58 \\
\hline & 6 & 5.6 & 121 & 106 & 117 & 81.82 & 4393.73 \\
\hline & 4 & 22.4 & 110 & 102 & 88 & 81.56 & 4235.46 \\
\hline & 3 & 57.4 & 114 & 104 & 76 & 81.42 & 4286.82 \\
\hline \multirow{4}{*}{0.8} & 8 & 0 & 130 & 100 & 139 & 81.91 & 4152.40 \\
\hline & 6 & 5.6 & 115 & 95 & 101 & 81.84 & 4085.61 \\
\hline & 4 & 22.4 & 104 & 93 & 76 & 81.58 & 3923.32 \\
\hline & 3 & 57.4 & 107 & 97 & 68 & 81.47 & 3988.54 \\
\hline
\end{tabular}

This is the largest amount that we would be willing to pay for knowledge of p.d.f. $f_{X}$ and this quantity can be regarded as the expected value additional information (EVAI) and a summary is presented in Table 6. It is noted that the cost performance of the distribution-free approach is improving as $\beta_{0}$ gets larger.
In practice, this ordering cost reduction model with backorder price discount at a retailer is more matched to real life supply chains. For example, in India, small scale industries spend an extra added cost by means of investment as well as allowing backorder price discount and it is expected to have a result to reduce the shortage cost of lost-sales and 
TABLE 5: Summary of the optimal solutions of Example 2 ( $L_{i}$ in weeks).

\begin{tabular}{cccccccccccc}
\hline$\beta_{0}$ & \multicolumn{4}{c}{ The proposed model } & \multicolumn{5}{c}{ Model with fixed $A$ and without $\pi$} \\
& $L_{*}$ & $Q_{*}$ & $A_{*}$ & $r_{*}$ & $\pi_{*}$ & JTEAC $(\cdot)$ & $L_{*}$ & $r_{*}$ & $Q_{*}$ & EAC $(\cdot)$ & Saving $(\%)$ \\
0.2 & 4 & 119 & 122 & 94 & 81.32 & 4795.67 & 3 & 183 & 72 & 5697.95 & 15.84 \\
0.4 & 4 & 115 & 116 & 82 & 81.38 & 4467.81 & 3 & 174 & 64 & 5354.01 & 16.55 \\
0.6 & 3 & 110 & 102 & 88 & 81.56 & 4235.46 & 4 & 163 & 74 & 5082.14 & 16.66 \\
0.8 & 3 & 104 & 93 & 76 & 81.58 & 3923.32 & 4 & 157 & 67 & 4810.65 & 18.45 \\
\hline
\end{tabular}

TABLE 6: Calculation of EVAI.

\begin{tabular}{lcccc}
\hline$\beta_{0}$ & $\operatorname{JTEAC}^{N}\left(Q_{*}, A_{*}, k_{*}, \pi_{*}, L_{*}\right)$ & $\mathrm{JTEAC}^{N}\left(Q^{*}, A^{*}, k^{*}, \pi^{*}, L^{*}\right)$ & EVAI & Cost penalty \\
\hline 0.2 & 3966.32 & 3684.56 & 281.76 & 1.076 \\
0.4 & 3843.43 & 3622.36 & 221.07 & 1.061 \\
0.6 & 3752.64 & 3543.28 & 209.36 & 1.059 \\
0.8 & 3681.72 & 3490.32 & 191.40 & 1.054 \\
\hline
\end{tabular}

the joint total annual expected cost. Again the goal of justin-time (JIT) from the inventory management standpoint is to produce small-lot sizes with reduced lost-sales and order cost. Investing capital in shortening lead time, reducing order cost, and allowing backorder price discount are regarded as the most effective means of achieving this goal and also we can lower the safety stock, reduce the out of stock loss, and improve the customer service level so as to gain competitive advantages in business.

\section{Concluding Remarks}

In the real market, as unsatisfied demands occur, the longer the length of lead time is, the smaller the proportion of backorder would be. Under probabilistic demand, inventory shortage is unavoidable. In order to make up for the inconvenience and even the losses of royal and patient customers, the supplier may offer a backorder price discount to secure orders during the shortage period. Also, ordering policies determined by conventional inventory models may be inappropriate for the situation in which an arrival lot contains some defective items. The purpose of this paper is to examine the effect of defective arrivals on an integrated inventory model by allowing the backorder price discount and order cost as decision variables. We first assume that the lead time demand follows a normal distribution and then relax this assumption by only assuming that the first two moments of the lead time demand are given and then solve this inventory model by using minimax distribution-free approach and, for each model, separate efficient computational algorithm is constructed to find the optimal solutions. Our algorithm is easy to use and mathematically sound.

Since the marketing environment is continuously changing, corporate strategy must be adjusted accordingly. If the ordering cost could be reduced effectively and if orders could be secured well, the total relevant cost per unit time could be automatically improved. On the other hand, if the buyer permits seller bigger backorder price discount, then it will be allowed to promote the service level and to reduce total expected annual cost. This paper fulfills the above literature gaps. Since our criterion is supported by the numerical examples, from the practical point of view, it is valid and useful to the competitive business.

By computing the proposed models, specifically, from the results of numerical examples, we observe that a significant amount of savings can be easily achieved. Also it shows that when there is an investing option of improving the system, it is advisable to invest. Computational results reveal the serious impact of inferior supply quality on system cost as well as the sensitivity of the system parameters. This model contributes an application in an inventory system consisting of ordering quantity, inspections, and defective items. The proposed model further fits a more general inventory feature in many real-life situations. In future research on this problem, it would be interesting research topic to deal with the inventory model with a service level constraint.

\section{Appendices}

\section{A. Proof of Proposition 1}

We want to prove the Hessian matrix of $\operatorname{JTEAC}^{N}(Q, \pi, k, A, L)$ at point $\left(Q^{*}, \pi^{*}, k^{*}\right)$ for fixed $A$ and $L \in\left[L_{i}, L_{i-1}\right]$ is positive definite. We first obtain the Hessian matrix $\mathbf{H}$ as follows:

$$
\mathbf{H}=\left(\begin{array}{ccc}
\frac{\partial^{2} \operatorname{JTEAC}^{N}(\cdot)}{\partial Q^{2}} & \frac{\partial^{2} \operatorname{JTEAC}^{N}(\cdot)}{\partial Q \partial \pi} & \frac{\partial^{2} \operatorname{JTEAC}^{N}(\cdot)}{\partial Q \partial k} \\
\frac{\partial^{2} \operatorname{JTEAC}^{N}(\cdot)}{\partial \pi \partial Q} & \frac{\partial^{2} \operatorname{JTEAC}^{N}(\cdot)}{\partial \pi^{2}} & \frac{\partial^{2} \operatorname{JTEAC}^{N}(\cdot)}{\partial \pi \partial k} \\
\frac{\partial^{2} \operatorname{JTEAC}^{N}(\cdot)}{\partial k \partial Q} & \frac{\partial^{2} \operatorname{JTEAC}^{N}(\cdot)}{\partial k \partial \pi} & \frac{\partial^{2} \operatorname{JTEAC}^{N}(\cdot)}{\partial k^{2}}
\end{array}\right)
$$


where

$$
\begin{aligned}
& \frac{\partial^{2} \operatorname{TTEAC}^{N}(\cdot)}{\partial Q^{2}} \\
& =\frac{2 D}{Q^{3}(1-E(p))}[A+C(L)] \\
& +\frac{D}{Q^{3}(1-E(p))}\left[A+C(L)+\left(\frac{\beta_{0} \pi^{2}}{\pi_{0}}+\pi_{0}-\beta_{0} \pi\right)\right] \\
& \times \sigma \sqrt{L} \psi(k), \\
& \frac{\partial^{2} \operatorname{JEAC}^{N}(\cdot)}{\partial \pi^{2}}=\frac{2 D \beta_{0}}{Q \pi_{0}} \sigma \sqrt{L} \psi(k), \\
& \frac{\partial^{2} \operatorname{JTEAC}^{N}(\cdot)}{\partial k^{2}} \\
& =\left[h\left(1-\frac{\beta_{0} \pi}{\pi_{0}}\right)+\frac{D}{Q(1-E(p))}\left(\frac{\beta_{0} \pi^{2}}{\pi_{0}}+\pi_{0}-\beta_{0} \pi\right)\right] \\
& \times \sigma \sqrt{L} P_{z}(k), \\
& \frac{\partial^{2} \operatorname{TTEAC}^{N}(\cdot)}{\partial Q \partial \pi} \\
& =\frac{\partial^{2} \operatorname{JTEAC}^{N}(\cdot)}{\partial \pi \partial Q} \\
& =-\frac{D}{2 Q^{2}(1-E(p))}\left(\frac{2 \beta_{0} \pi}{\pi_{0}}-\beta_{0}\right) \sigma \sqrt{L} \psi(k), \\
& \frac{\partial^{2} \operatorname{JTEAC}^{N}(\cdot)}{\partial k \partial \pi} \\
& =\frac{\partial^{2} \operatorname{JTEAC}^{N}(\cdot)}{\partial \pi \partial k} \\
& =\left[h \frac{\beta_{0}}{\pi_{0}}-\frac{D}{Q}\left(\frac{2 \beta_{0} \pi}{\pi_{0}}-\beta_{0}\right)\right] \sigma \sqrt{L}(1-\Phi(k)), \\
& \frac{\partial^{2} \operatorname{JTEAC}^{N}(\cdot)}{\partial Q \partial k} \\
& =\frac{\partial^{2} \operatorname{JTEAC}^{N}(\cdot)}{\partial k \partial Q} \\
& =\frac{D}{Q^{2}(1-E(p))}\left(\frac{\beta_{0} \pi^{2}}{\pi_{0}}+\pi_{0}-\beta_{0} \pi\right) \\
& \times \sigma \sqrt{L}(1-\Phi(k)),
\end{aligned}
$$

and $\operatorname{JTEAC}^{N}(\cdot)=\operatorname{JTEAC}^{N}(Q, \pi, k, A, L)$.
Then we proceed by evaluating the principal minor determinants of $\mathbf{H}$ at point $\left(Q^{*}, \pi^{*}, k^{*}\right)$. Now, the first principal minor determinant of $\mathbf{H}$ is

$$
\begin{aligned}
\left|\mathbf{H}_{11}\right| & \frac{2 D}{Q^{* 3}(1-E(p))}[A+C(L)] \\
& +\frac{D}{Q^{* 3}(1-E(p))}\left[A+C(L)+\left(\frac{\beta_{0} \pi^{* 2}}{\pi_{0}}+\pi_{0}-\beta_{0} \pi^{*}\right)\right] \\
& \times \sigma \sqrt{L} \psi\left(k^{*}\right)>0 .
\end{aligned}
$$

The second principal minor determinant of $\mathbf{H}$ is

$$
\begin{aligned}
& \left|\mathbf{H}_{22}\right| \\
& =\left|\begin{array}{ll}
\frac{\partial^{2} \operatorname{JTEAC}^{N}(\cdot)}{\partial Q^{2}} & \frac{\partial^{2} \operatorname{JTEAC}^{N}(\cdot)}{\partial Q \partial \pi} \\
\frac{\partial^{2} \operatorname{JTEAC}^{N}(\cdot)}{\partial \pi \partial Q} & \frac{\partial^{2} \operatorname{JTEAC}^{N}(\cdot)}{\partial \pi^{2}}
\end{array}\right| \\
& =\left(\frac{\partial^{2} \operatorname{TTEAC}^{N}(\cdot)}{\partial Q^{2}}\right)\left(\frac{\partial^{2} \operatorname{TTEAC}^{N}(\cdot)}{\partial \pi^{2}}\right)-\left(\frac{\partial^{2} \operatorname{TTEAC}^{N}(\cdot)}{\partial Q \partial \pi}\right)^{2} \\
& =\left\{\frac{2 D}{Q^{* 3}(1-E(p))}\right. \\
& \left.\times\left[A+C(L)+\left(\frac{\beta_{0} \pi^{* 2}}{\pi_{0}}+\pi_{0}-\beta_{0} \pi^{*}\right)\right]\right\} \\
& \times\left\{\frac{2 D \beta_{0}}{Q^{*} \pi_{0}} \sigma \sqrt{L} \psi\left(k^{*}\right)\right\} \\
& -\left\{\frac{D}{Q^{* 2}(1-E(p))}\left(\frac{2 \beta_{0} \pi^{*}}{\pi_{0}}-\beta_{0}\right) \sigma \sqrt{L} \psi\left(k^{*}\right)\right\}^{2} \\
& =\frac{2 D^{2} \beta_{0}}{Q^{* 4}(1-E(p)) \pi_{0}}(A+C(L)) \sigma \sqrt{L} \psi\left(k^{*}\right) \\
& +\frac{D^{2} \beta_{0}}{Q^{* 4}(1-E(p))}\left(1-\frac{\beta_{0}}{4}\right)\left(\sigma \sqrt{L} \psi\left(k^{*}\right)\right)^{2}>0 .
\end{aligned}
$$

Consequently, after substituting $\pi^{*}$, by expanding and simplifying further, the third principal minor of $\mathbf{H}$ is

$$
\left|\mathbf{H}_{33}\right|=\left|\begin{array}{lll}
\frac{\partial^{2} \operatorname{JTEAC}^{N}(\cdot)}{\partial Q^{2}} & \frac{\partial^{2} \operatorname{JTEAC}^{N}(\cdot)}{\partial Q \partial \pi} & \frac{\partial^{2} \operatorname{JTEAC}^{N}(\cdot)}{\partial Q \partial k} \\
\frac{\partial^{2} \operatorname{JTEAC}^{N}(\cdot)}{\partial \pi \partial Q} & \frac{\partial^{2} \operatorname{JTEAC}^{N}(\cdot)}{\partial \pi^{2}} & \frac{\partial^{2} \operatorname{JTEAC}^{N}(\cdot)}{\partial \pi \partial k} \\
\frac{\partial^{2} \operatorname{JTEAC}^{N}(\cdot)}{\partial k \partial Q} & \frac{\partial^{2} \operatorname{JTEAC}^{N}(\cdot)}{\partial k \partial \pi} & \frac{\partial^{2} \operatorname{JTEAC}^{N}(\cdot)}{\partial k^{2}}
\end{array}\right| ;
$$

we see that $\left|\mathbf{H}_{33}\right|>0$. Hence, it is concluded that the Hessian matrix $\mathbf{H}$ is positive definite at point $\left(Q^{*}, \pi^{*}, k^{*}\right)$. 


\section{B. Proof of Proposition 3}

We want to prove the Hessian matrix of $\operatorname{JTEAC}^{U}(Q, \pi, k, A, L)$ at point $\left(Q_{*}, \pi_{*}, k_{*}\right)$ for fixed $A$ and $L \in\left[L_{i}, L_{i-1}\right]$ is positive definite. We first obtain the Hessian matrix $\mathbf{H}$ as follows:

$$
\mathbf{H}=\left(\begin{array}{ccc}
\frac{\partial^{2} \operatorname{JTEAC}^{U}(\cdot)}{\partial Q^{2}} & \frac{\partial^{2} \operatorname{JTEAC}^{U}(\cdot)}{\partial Q \partial \pi} & \frac{\partial^{2} \operatorname{JTEAC}^{U}(\cdot)}{\partial Q \partial k} \\
\frac{\partial^{2} \operatorname{JTEAC}^{U}(\cdot)}{\partial \pi \partial Q} & \frac{\partial^{2} \operatorname{JTEAC}^{U}(\cdot)}{\partial \pi^{2}} & \frac{\partial^{2} \operatorname{JTEAC}^{U}(\cdot)}{\partial \pi \partial k} \\
\frac{\partial^{2} \operatorname{JTEAC}^{U}(\cdot)}{\partial k \partial Q} & \frac{\partial^{2} \operatorname{JTEAC}^{U}(\cdot)}{\partial k \partial \pi} & \frac{\partial^{2} \operatorname{JTEAC}^{U}(\cdot)}{\partial k^{2}}
\end{array}\right),
$$

where

$$
\begin{aligned}
& \frac{\partial^{2} \mathrm{JTEAC}^{U}(\cdot)}{\partial Q^{2}} \\
& =\frac{2 D}{Q^{3}(1-E(p))}[A+C(L)] \\
& \quad+\frac{D}{Q^{3}(1-E(p))}\left[\frac{\beta_{0} \pi^{2}}{\pi_{0}}+\pi_{0}-\beta_{0} \pi\right] \\
& \quad \times \sigma \sqrt{L}\left(\sqrt{1+k^{2}}-k\right), \\
& \frac{\partial^{2} \mathrm{JTEAC}^{U}(\cdot)}{\partial \pi^{2}}=\frac{D \beta_{0}}{Q \pi_{0}} \sigma \sqrt{L}\left(\sqrt{1+k^{2}}-k\right), \\
& \frac{\partial^{2} \mathrm{JTEAC}^{U}(\cdot)}{\partial k^{2}} \\
& =\frac{1}{2}\left[h\left(1-\frac{\beta_{0} \pi}{\pi_{0}}\right)+\frac{D}{Q(1-E(p))}\left(\frac{\beta_{0} \pi^{2}}{\pi_{0}}+\pi_{0}-\beta_{0} \pi\right)\right] \\
& \quad \times \sigma \sqrt{L}\left(1+k^{2}\right)^{-3 / 2}, \\
& \frac{\partial^{2} \mathrm{JTEAC}^{U}(\cdot)}{\partial Q \partial \pi} \\
& =\frac{\partial^{2} \mathrm{JTEAC}(\cdot)}{\partial \pi \partial Q} \\
& =\frac{\partial^{2} \mathrm{JTEAC}^{U}(\cdot)}{\partial k \partial \pi}\left[h \frac{\beta_{0}}{\pi_{0}}-\frac{D}{\mathrm{Q}}\left(\frac{2 \beta_{0} \pi}{\pi_{0}}-\beta_{0}\right)\right] \sigma \sqrt{L}\left(1-\frac{k}{\sqrt{1+k^{2}}}\right), \\
& \quad \times \sigma \sqrt{L}\left(\sqrt{1+k^{2}}-k\right), \\
& \left.=\frac{2 \beta_{0} \pi}{\pi_{0}}-\beta_{0}\right)
\end{aligned}
$$

$$
\begin{aligned}
& \frac{\partial^{2} \operatorname{JTEAC}^{U}(\cdot)}{\partial Q \partial k} \\
& =\frac{\partial^{2} \operatorname{JTEAC}^{U}(\cdot)}{\partial k \partial Q} \\
& =\frac{D}{Q^{2}(1-E(p))}\left(\frac{\beta_{0} \pi^{2}}{\pi_{0}}+\pi_{0}-\beta_{0} \pi\right) \\
& \quad \times \sigma \sqrt{L}\left(1-\frac{k}{\sqrt{1+k^{2}}}\right),
\end{aligned}
$$

and $\operatorname{JTEAC}(\cdot)=\operatorname{JTEAC}(Q, \pi, k, A, L)$

Then we proceed to evaluate the principal minor determinants of $\mathbf{H}$ at point $\left(Q^{*}, \pi^{*}, k^{*}\right)$. Now, the first principal minor determinant of $\mathbf{H}$ is

$$
\begin{aligned}
& \left|\mathbf{H}_{11}\right| \\
& =\frac{2 D}{Q^{* 3}(1-E(p))}[A+C(L)] \\
& \quad+\frac{D}{Q^{* 3}(1-E(p))}\left[\frac{\beta_{0} \pi^{* 2}}{\pi_{0}}+\pi_{0}-\beta_{0} \pi^{*}\right] \\
& \quad \times \sigma \sqrt{L}\left(\sqrt{1+k^{* 2}}-k^{*}\right)>0 .
\end{aligned}
$$

The second principal minor determinant of $\mathbf{H}$ is

$\left|\mathbf{H}_{22}\right|$

$$
\begin{aligned}
= & \left|\begin{array}{ll}
\frac{\partial^{2} \operatorname{JTEAC}^{U}(\cdot)}{\partial Q^{2}} & \frac{\partial^{2} \operatorname{JTEAC}^{U}(\cdot)}{\partial Q \partial \pi} \\
\frac{\partial^{2} \operatorname{JTEAC}^{U}(\cdot)}{\partial \pi \partial Q} & \frac{\partial^{2} \operatorname{JTEAC}^{U}(\cdot)}{\partial \pi^{2}} \mid
\end{array}\right| \\
= & \left(\frac{\partial^{2} \operatorname{JTEAC}^{U}(\cdot)}{\partial Q^{2}}\right)\left(\frac{\partial^{2} \operatorname{JTEAC}^{U}(\cdot)}{\partial \pi^{2}}\right)-\left(\frac{\partial^{2} \operatorname{JTEAC}^{U}(\cdot)}{\partial Q \partial \pi}\right)^{2} \\
= & \left\{\frac{2 D}{Q^{* 3}(1-E(p))}\right. \\
& \left.\times\left[A+C(L)+\left(\frac{\beta_{0} \pi^{* 2}}{\pi_{0}}+\pi_{0}-\beta_{0} \pi^{*}\right)\right]\right\} \\
& +\left\{\frac{2 D \beta_{0}}{Q^{*} \pi_{0}} \sigma \sqrt{L}\left(\sqrt{1+k^{* 2}}-k\right)\right\} \\
= & \left.\frac{2 Q^{* 2}(1-E(p))}{Q^{* 4}(1-E(p)) \pi_{0}}\left[\frac{2 \beta_{0} \pi}{\pi_{0}}-\beta_{0}\right) \sigma \sqrt{L}\left(\sqrt{1+k^{* 2}}-k\right)\right\}^{2} \\
& +\frac{D^{2} \beta_{0}}{Q^{* 4}(1-E(p))}\left(1-\frac{\beta_{0}}{4}\right)\left(\sigma \sqrt{L}\left(\sqrt{1+k^{* 2}}-k^{*}\right)^{2}>0 .\right.
\end{aligned}
$$


Consequently, after substituting $\pi^{*}$, by expanding and simplifying further, the third principal minor of $\mathbf{H}$ is

$$
\left|\mathbf{H}_{33}\right|=\left|\begin{array}{lll}
\frac{\partial^{2} \operatorname{JTEAC}^{U}(\cdot)}{\partial Q^{2}} & \frac{\partial^{2} \operatorname{JTEAC}^{U}(\cdot)}{\partial Q \partial \pi} & \frac{\partial^{2} \operatorname{JTEAC}^{U}(\cdot)}{\partial Q \partial k} \\
\frac{\partial^{2} \operatorname{JTEAC}^{U}(\cdot)}{\partial \pi \partial Q} & \frac{\partial^{2} \operatorname{JTEAC}^{U}(\cdot)}{\partial \pi^{2}} & \frac{\partial^{2} \operatorname{JTEAC}^{U}(\cdot)}{\partial \pi \partial k} \\
\frac{\partial^{2} \operatorname{JTEAC}^{U}(\cdot)}{\partial k \partial Q} & \frac{\partial^{2} \operatorname{JTAC}^{U}(\cdot)}{\partial k \partial \pi} & \frac{\partial^{2} \operatorname{JTAC}^{U}(\cdot)}{\partial k^{2}}
\end{array}\right|
$$

and we see that $\left|\mathbf{H}_{33}\right|>0$.

Hence, it is concluded that the Hessian matrix $\mathbf{H}$ is positive definite at point $\left(Q_{*}, \pi_{*}, k_{*}\right)$.

\section{Conflict of Interests}

The authors declare that there is no conflict of interests regarding the publication of this paper.

\section{Acknowledgments}

The authors are grateful to the anonymous reviewers and the editor for their insightful and constructive comments and helpful suggestions, which have led to a significant improvement in the earlier version of the paper. Best efforts have been made by the authors to revise the paper abiding by the constructive comments of the reviewers.

\section{References}

[1] C. J. Liao and C. H. Shyu, "An analytical determination of lead time with normal demand," International Journal of Operations \& Production Management, vol. 11, no. 9, pp. 72-78, 1991.

[2] M. Ben-Daya and A. Raouf, "Inventory models involving lead time as a decision variable," Journal of the Operational Research Society, vol. 45, no. 5, pp. 579-582, 1994.

[3] L.-Y. Ouyang and K.-S. Wu, "A minimax distribution free procedure for mixed inventory model with variable lead time," International Journal of Production Economics, vol. 56-57, pp. 511-516, 1998.

[4] L.-Y. Ouyang, C.-K. Chen, and H.-C. Chang, "Lead time and ordering cost reductions in continuous review inventory systems with partial backorders," Journal of the Operational Research Society, vol. 50, no. 12, pp. 1272-1279, 1999.

[5] L. Y. Ouyang and B. R. Chuang, "A periodic review inventory model involving variable lead time with a service level constraint," International Journal of System Science, vol. 31, pp. 1209$1215,2000$.

[6] L.-Y. Ouyang, K.-S. Wu, and C.-H. Ho, "An integrated vendorbuyer inventory model with quality improvement and lead time reduction," International Journal of Production Economics, vol. 108, no. 1-2, pp. 349-358, 2007.

[7] G. Yang, R. J. Ronald, and P. Chu, "Inventory models with variable lead time and present value," European Journal of Operational Research, vol. 164, no. 2, pp. 358-366, 2005.

[8] W.-C. Lee, "Inventory model involving controllable backorder rate and variable lead time demand with the mixtures of distribution," Applied Mathematics and Computation, vol. 160, no. 3, pp. 701-717, 2005.

[9] M. A. Hoque and S. K. Goyal, "An alternative simple solution algorithm of an inventory model with fixed and variable lead time crash costs under unknown demand distribution," International Journal of Systems Science. Principles and Applications of Systems and Integration, vol. 40, no. 8, pp. 821-827, 2009.

[10] K. Annadurai and R. Uthayakumar, "Controlling setup cost in $(Q, r, L)$ inventory model with defective items," Applied Mathematical Modelling: Simulation and Computation for Engineering and Environmental Systems, vol. 34, no. 6, pp. 1418-1427, 2010.

[11] J. C.-H. Pan and Y.-C. Hsiao, "Integrated inventory models with controllable lead time and backorder discount considerations," International Journal of Production Economics, vol. 93-94, pp. 387-397, 2005.

[12] W.-C. Lee, J.-W. Wu, and C.-L. Lei, "Computational algorithmic procedure for optimal inventory policy involving ordering cost reduction and back-order discounts when lead time demand is controllable," Applied Mathematics and Computation, vol. 189, no. 1, pp. 186-200, 2007.

[13] Y.-J. Lin, "Minimax distribution free procedure with backorder price discount," International Journal of Production Economics, vol. 111, no. 1, pp. 118-128, 2008.

[14] R. Uthayakumar and P. Parvathi, "A continuous review inventory model with controllable backorder rate and investments," International Journal of Systems Science, vol. 40, no. 3, pp. 245254, 2009.

[15] B. Sarkar, S. S. Sana, and K. S. Chaudhuri, "An inventory model with finite replenishment rate, trade credit policy and price-discount offer," Journal of Industrial Engineering, vol. 2013, Article ID 672504, 18 pages, 2013.

[16] M. J. Paknejad, F. Nasri, and J. F. Affiso, "Defective units in a continuous review $(s, Q)$ system," International Journal of Production Research, vol. 33, no. 10, pp. 2767-2777, 1995.

[17] L.-Y. Ouyang and K.-S. Wu, "Mixture inventory model involving variable lead time and defective units," Journal of Statistics \& Management Systems, vol. 2, no. 2-3, pp. 143-157, 1999.

[18] K.-S. Wu and L.-Y. Ouyang, "(Q, r, L) inventory model with defective items," Computers and Industrial Engineering, vol. 39, no. 1-2, pp. 173-185, 2001.

[19] S. S. Sana, S. K. Goyal, and K. Chaudhuri, "An imperfect production process in a volume flexible inventory model," International Journal of Production Economics, vol. 105, no. 2, pp. 548-559, 2007.

[20] B. Sarkar, K. Chaudhuri, and S. S. Sana, "A stock-dependent inventory model in an imperfect production process," International Journal of Procurement Management, vol. 3, no. 4, pp. 361378, 2010.

[21] B. Sarkar, S. S. Sana, and K. Chaudhuri, "An economic production quantity model with stochastic demand in an imperfect production system," International Journal of Services and Operations Management, vol. 9, no. 3, pp. 259-283, 2011.

[22] W. C. Lee, J. W. Wu, H. H. Tsou, and C. L. Lei, "Computational procedure of optimal inventory model involving controllable backorder rate and variable lead time with defective units," International Journal of Systems Science, vol. 43, no. 10, pp. 19271942, 2012.

[23] K. Skouri, I. Konstantaras, A. G. Lagodimos, and S. Papachristos, "An EOQ model with backorders and rejection of defective supply batches," International Journal of Production Economics, vol. 155, pp. 148-154, 2013. 
[24] R. L. Schwaller, "EOQ under inspection costs," Production and Inventory Management Journal, vol. 29, no. 3, pp. 22-24, 1988.

[25] R. W. Hall, Zero Inventories, Dow Jones Irwin, Homewood, Ill, USA, 1983.

[26] F. Nasri, J. F. Affisco, and M. J. Paknejad, "Setup cost reduction in an inventory model with finite-range stochastic lead times," International Journal of Production Research, vol. 28, no. 1, pp. 199-212, 1990.

[27] G. Gallego and I. Moon, "Distribution free newsboy problem: review and extensions," Journal of the Operational Research Society, vol. 44, no. 8, pp. 825-834, 1993. 


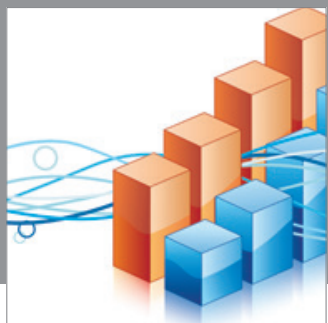

Advances in

Operations Research

mansans

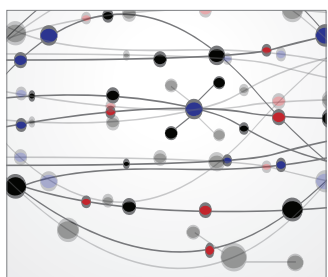

The Scientific World Journal
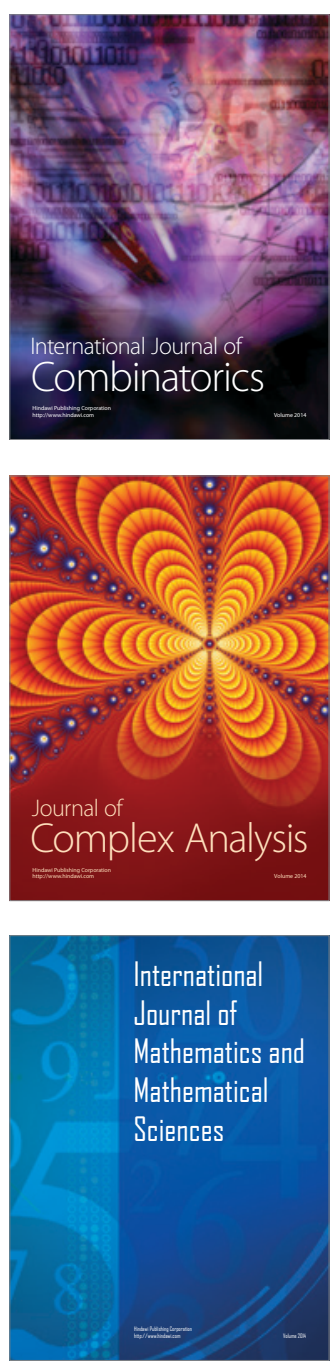
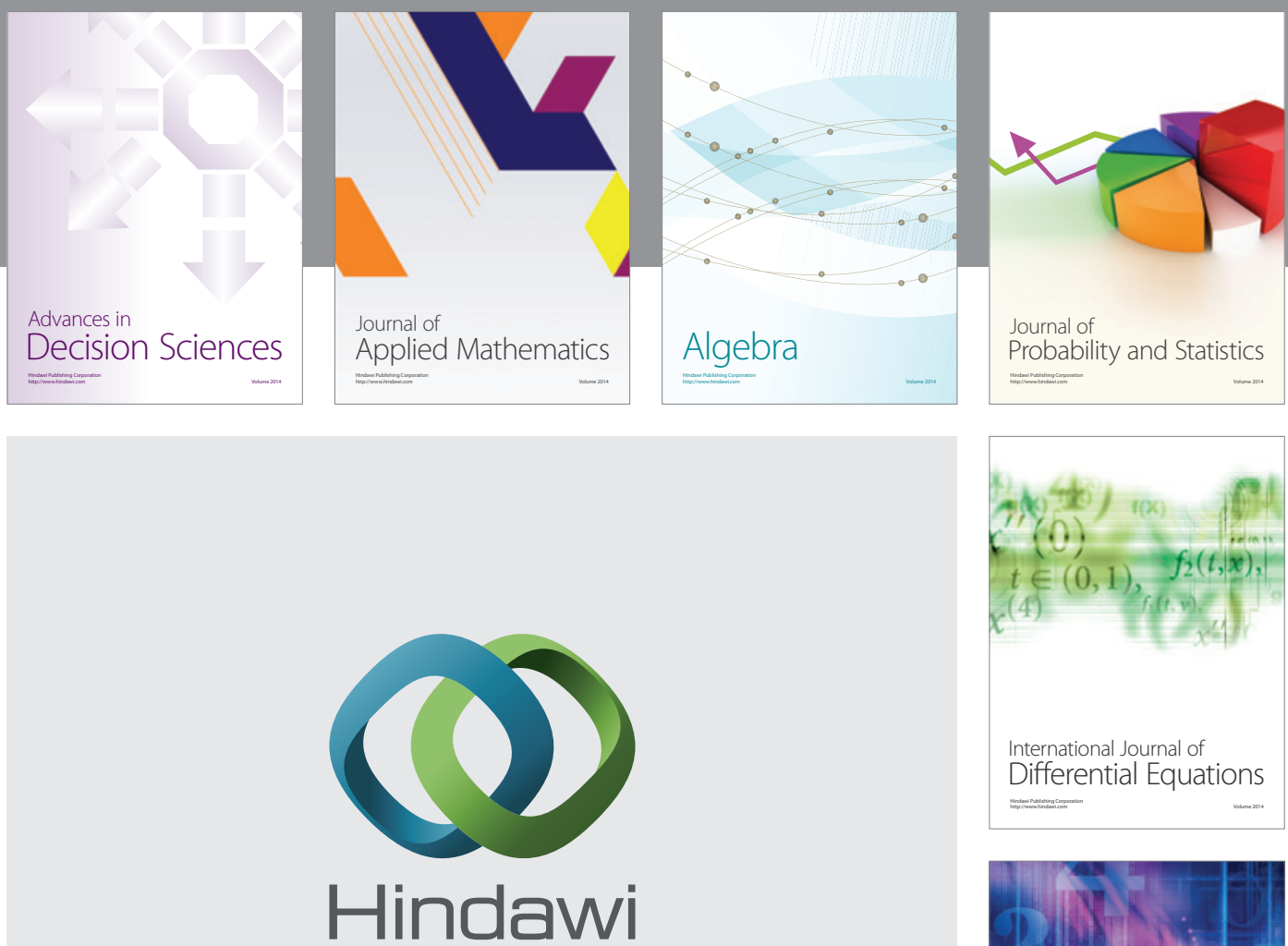

Submit your manuscripts at http://www.hindawi.com
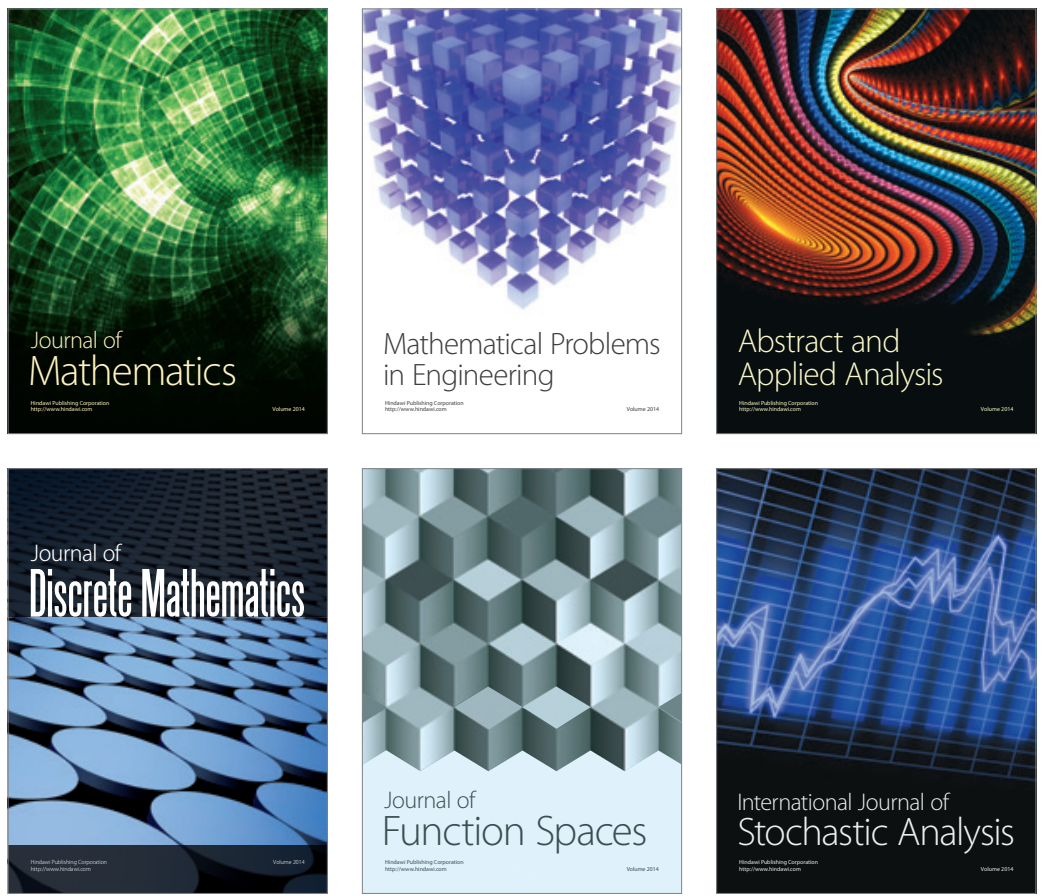

Journal of

Function Spaces

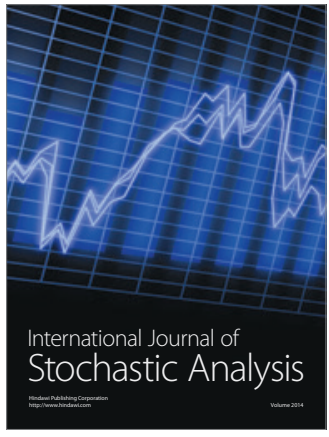

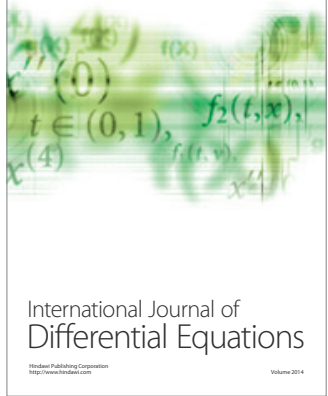
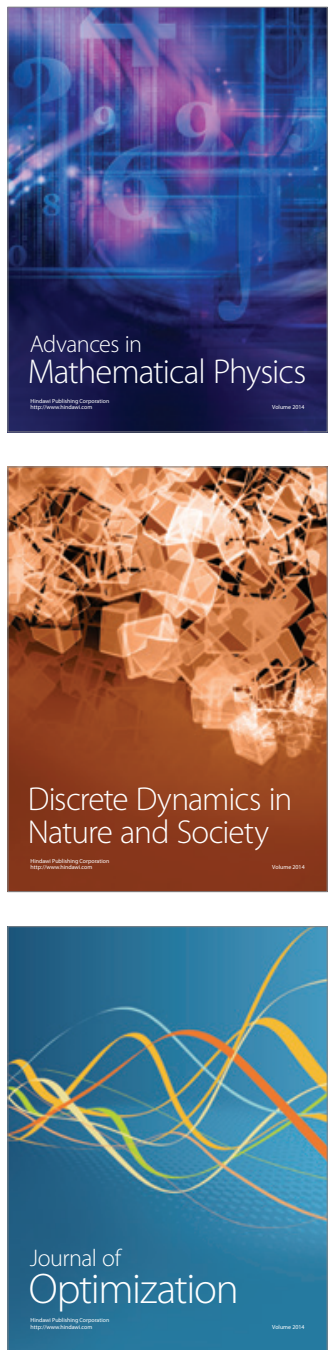